\title{
ANALISA PENEMPATAN DAN KEBUTUHAN PROTEKSI KATODIK PADA SISTEM PIPA GAS BAWAH LAUT OFFSHORE DARI PULAU PEMPING KE TANJUNG UNCANG BATAM
}

\author{
*Nur Azisah, Daeng Paroka dan Wahyuddin \\ Departemen Teknik Kelautan Universitas Hasanuddin \\ *asisah18@yahoo.com
}

\begin{abstract}
Abstrak
Korosi merupakan suatu permasalahan yang sering terjadi pada rangkaian pipa bawah laut. Hal ini dikarenakan material pipa logam yang dipasang di lingkungan yang memiliki tingkat korosifitas tinggi. Walaupun korosi tidak dapat dihindari atau dihilangkan, namun dapat dikendalikan untuk meminimalisir kerusakan pada pipa dengan melakukan perancangan proteksi katodik. Salah satunya adalah dengan menggunakan metode anoda korban. Penelitian ini bertujuan untuk membuat rancangan pengendalian laju korosi pada pipa bawah laut sepanjang 13,5 km, berdiameter 16 inci untuk umur desain 45 tahun dimana kebutuhan proteksi tiap meter pipa dianggap sama. Anoda yang digunakan adalah anoda gelang dengan panjang $400 \mathrm{~mm}$ dan tebal $40 \mathrm{~mm}$ yang berbahan paduan aluminium. Dalam perancangan proteksi katodik ini, penulis mengacu pada ketentuan DNVGL-F103 dan ISO 15589-2. Dari hasil penelitian ini, akan di dapatkan total anoda yang dibutuhkan untuk memproteksi pipa serta jarak pemasangan antar anoda. Berdasarkan total anoda tersebut, dapat diketahui estimasi biaya yang diperlukan dalam pembuatan proteksi katodik.
\end{abstract}

Kata Kunci: Pipa, Proteksi, Korosi, Anoda Korban, DNVGL, ISO.

\begin{abstract}
Abstarct
Corrosion is a problem that often occurs in submarine pipelines. This is because the metal pipe material is installed in environments that have a high level of corrosivity. Although corrosion cannot be avoided or eliminated, it can be controlled by cathodic protection. One of them is the sacrificial anode method. The aim of this research is to design a corrosion rate control in an underwater pipe along $13.5 \mathrm{~km}$, with a diameter of 16 inches for a design life of 45 years. The anode used is a $400 \mathrm{~mm}$ long and $40 \mathrm{~mm}$ thick anode made of aluminum alloy. In designing this cathodic protection, the writer refers to DNVGL-F103 and ISO 15589-2. From the results of this study, we will get the total anode needed to protect the pipe and the installation distance between the anodes. Based on the total anode, it can be seen the estimated cost needed in making cathodic protection.
\end{abstract}

Keyword: Pipe, Protection, Corrosion, Sacrificial Anode, DNVGL, ISO.

\section{PENDAHULAN}

Daerah pengoperasian struktur mempunyai pengaruh yang berbeda-beda terhadap penyerangan korosi. Beberapa kandungan air laut yang mempengaruhi tingkat korosi antara lain: salinitas, temperatur, dan zat-zat yang terkandung di dalamnya seperti gas-gas yang terlarut [1][2].

Korosi merupakan salah satu masalah utama dalam dunia industri. Tentunya karena korosi menyebabkan kegagalan pada material yang berujung pada kerusakan pada peralatan atau kegagalan pada operasi yang menimbulkan kerugian yang tidak sedikit seperti pada gambar 1. Pengendalian korosi dapat dilakukan dengan berbagai cara. Untuk mengendalikan serangan korosi internal dibagian dalam pipa, dapat dilakukan dengan menggunakan metode lining atau menggunakan inhibitor [3][4]. Untuk mencegah korosi pada bagian luar pipa dapat dilakukan dengan cara mengubah ingkungan sekitar pipa menjadi tidak korosif. Upaya lain untuk mengendalikan serangan korosi pada bagian luar pipa juga dapat dilakukan dengan menggunakan coating. 
Selain kedua metode tersebut, pengendalian korosi dapat menggunakan sistem proteksi katodik. Proteksi katodik dapat dilakukan dengan 2 cara yaitu metode impressed current dan metode anoda korban (sacrificial/galvanic anode) [5].

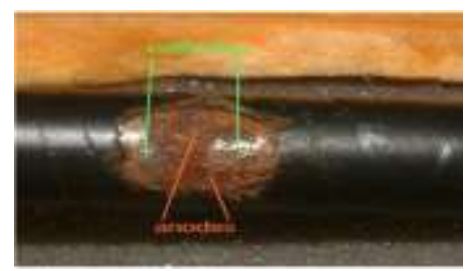

Gambar 1. Korosi [9]

Sistem proteksi katodik menggunakan metode Sacrificial Anode (anoda korban) yang disimulasikan untuk mengevaluasi kinerja Sistim Pipa Gas Bawah Laut Diameter 16" Sepanjang + 13.5 Km Dari Orf Di Pulau Pemping Ke Plant Gate Pembangkit Listrik Tanjung Uncang. Pada perencanaan, pipa akan menerima beban yang berbeda (seperti beban gelombang) sehingga memerlukan penanganan (dalam hal ini perawatan dan juga pemberian sacrificial anoda) yang berbeda juga. Untuk itu dilakukan suatu analisis untuk mengetahui kebutuhan proteksi katodik dari sistem perpipaan bawah laut. Dari hasil analisis ini, diketahui kebutuhan lapisan proteksi katodik yang akan digunakan pada sistem perpipaan dan dibuat suatu perencanaan sistem pipa yang dapat sesuai dengan ketentuan pemesan dan dapat dipertanggung jawabkan.

\section{METODE}

Proteksi adalah perlindungan terhadap suatu benda agar benda tersebut dapat tetap bekerja dengan optimal tanpa adanya gangguan. Berbagai macam proteksi dilakukan oleh perusahan dan industri - industri salah satunya adalah proteksi katodik. Proteksi katodik adalah sebuah sistem proteksi dimana sebuah struktur dilindungi menggunakan metoda reaksi oksidasi yang terjadi pada 2 buah logam. Struktur yang dapat dilindungi oleh proteksi katodik memiliki banyak jenis diantaranya seperti pipa bawah tanah, tangki timbun ataupun tangki penyimpanan, bahkan bagian hulu kapal laut [6].

\subsection{Objek Penelitian}

Penelitian ini dilakukan untuk mengetahui jumlah proteksi katodik yang dibutuhkan pada Pipa gas 16 inci sepanjang $\pm 13,5 \mathrm{~km}$ yang dipasang dari Pulau Pemping (Pemping ORF) ke Tanjung Uncang (Batam ORF). Peta rute pemasangan dapat dilihat pada Gambar 2. Sistem pipa gas dirancang dengan tekanan 550-710 Psig pada titik yang diterima dengan kapasitas aliran gas maksimum 125 MMscfd untuk memenuhi kebutuhan transportasi di masa depan. Kedua belah pihak akan menggunakan volume gas ini untuk kepentingannya sendiri untuk menggerakkan pembangkit listrik turbin gas baru, yang akan dibangun di Tanjung Uncang Batam dengan kapasitas terpasang sekitar 210MW.

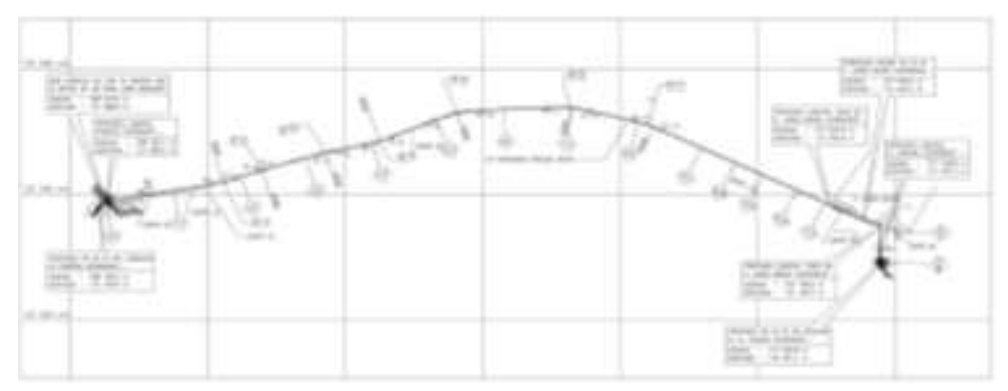

Gambar 2. Rute Pemasangan Pipa

\subsection{Metode Anode Korban}

Dalam penentuan hal tersebut, digunakan sebuah metode penentuan proteksi anoda pada pipa bawah laut yaitu metode sacrificial anode atau anoda korban. Sistem ini dikenal juga dengan galvanic anode, di mana cara kerja dan sumber arus yang digunakan berasal hanya dari reaksi galvanis anoda itu sendiri. Prinsip dasar dari sistem anoda korban adalah hanya dengan cara menciptakan sel elektrokimia galvanic dimana dua logam 
yang berbeda dihubungkan secara elektris dan ditanam dalam elektrolit alam (tanah atau air) [7]. Ada beberapa keuntungan yang diperoleh jika menggunakan sistem anoda korban, yaitu:

a. Tidak memerlukan arus tambahan dari luar, karena arus proteksi berasal dari anodanya itu sendiri

b. Pemasangan dilapangan relatif lebih sederhana

c. Perawatannya mudah

d. Ditinjau dari segi biaya, sistem ini lebih murah disbanding sistem arus tanding

e. Kemungkinan menimbulkan efek interfensi kecil

f. Kebutuhan material untuk sistem anoda korban relatif sedikit yaitu anoda, kabel, dan test box.

\subsection{Gelang Anoda}

Dalam desain perlindungan katodik, perhitungan akan dilakukan untuk memastikan anoda yang cukup tersedia untuk menyediakan total arus yang dibutuhkan untuk melindungi pipa selama masa desainnya. Kepadatan arus awal dan akhir diperiksa untuk memastikan bahwa anoda dapat memberikan keluaran arus yang cukup untuk mempolarisasi pipa sepanjang masa pakainya [8].

Desain perlindungan katodik yang di gunakan adalah ISO 15589-2 dan DNV RP F103. Sistem Perlindungan katodik yang akan digunakan adalah Half Shelf Sacrificial Anode, seperti yang terlihat pada gambar 3 untuk bagian offshore pipeline yang akan melindungi pipa sepanjang 13,5 km berdiameter 16 inci serta dengan umur desain berkisar selama 45 tahun.

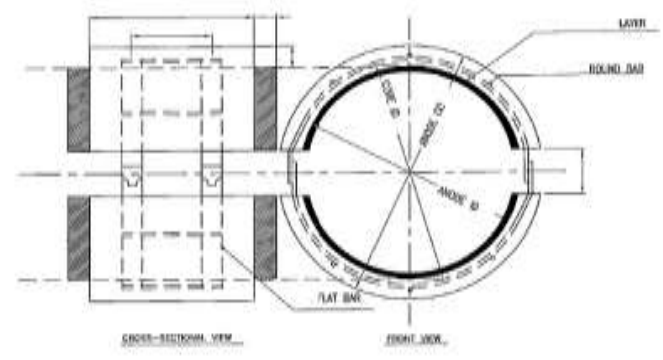

Gambar 3. Anoda Gelang (DNV-RP-F103)

Dalam desain perlindungan katodik, perhitungan akan dilakukan untuk memastikan anoda yang cukup tersedia untuk menyediakan total arus yang dibutuhkan untuk melindungi pipa selama masa desainnya. Kepadatan arus awal dan akhir diperiksa untuk memastikan bahwa anoda dapat memberikan keluaran arus yang cukup untuk mempolarisasi pipa sepanjang masa pakainya. Data anoda yang digunakan dapat dilihat pada tabel 1 .

\begin{tabular}{ll}
\hline Parameter & Nilai \\
\hline Celah gelang anoda $($ gap $)$ & $75 \mathrm{~mm}$ \\
Desain umur anoda & 45 Tahun \\
Jenis Bahan Anoda & Paduan aluminium (AI-Zinc-In) \\
Efisiensi Elektrokimia dalam Air Laut pada Suhu Sekitar $\left(25^{\circ} \mathrm{C}\right)$ & $2000 \mathrm{~A}-\mathrm{jam} / \mathrm{kg}$ \\
Ketebalan anoda $\left(\mathrm{t}_{\mathrm{a}}\right)$ & $40 \mathrm{~mm}$ \\
Massa jenis anoda $(\rho \mathrm{a})$ & $2750 \mathrm{~kg} / \mathrm{m}^{3}$ \\
Panjang anoda $\left(\mathrm{L}_{\mathrm{at}}\right)$ & $400 \mathrm{~mm}$ \\
Core thickness $\left(\mathrm{t}_{\mathrm{core}}\right)$ & $6 \mathrm{~mm}$ \\
Inti per anoda $\left(\mathrm{n}_{\mathrm{core}}\right)$ & 2 \\
Ketebalan lapisan internal anoda ( $\left.\mathrm{t}_{\mathrm{ac}}\right)$ & $0.1 \mathrm{~mm}$ \\
Resistivitas Di Air Laut. & $0,21 \mathrm{ohm}-\mathrm{m}$ (typical) \\
Faktor Pemanfaatan Anoda & 0.80 \\
Toleransi diameter luar pipa (ODtol) & $0 \mathrm{~mm}$ \\
Toleransi diameter dalam pipa (IDtol) & $0 \mathrm{~mm}$ \\
Toleransi fabrikasi (Ftol) & $0 \%$ \\
Lebar inti (Wcore) & $50 \mathrm{~mm}$ \\
Maksimum jarak antar anoda (sesuai spesifikasi) $\left(\mathrm{M}_{\mathrm{AS}}\right)$ & $300 \mathrm{~m}$ \\
\hline
\end{tabular}




\section{HASIL DAN PEMBAHASAN}

Perhitungan kebutuhan anoda membutuhkan beberapa kriteria desain sesuai permintaan. Kriteria tersebut antara lain adalah data pipeline (Tabel 1), data operasional pipa (Tabel 2) di lokasi pemasangan pipa yaitu dari Pulau Pemping (Pemping ORF) ke Tanjung Uncang (Batam ORF) dan data anoda yang akan dipasang (Tabel $3)$.

Tabel 1. Data Propertis Pipa dan Material yang Digunakan

\begin{tabular}{lll}
\hline Parameter & Unit & Nilai \\
\hline Panjang Pipa $( \pm)$ & $\mathrm{km}$ & 13.5 \\
Diameter luar pipa & $\mathrm{mm}$ (inch) & $406.4(16)$ \\
Ketebalan dinding pipa & $\mathrm{mm}$ (inch) & $12.7(0.5)$ \\
Spesifikasi material & - & Carbon Steel \\
Tebal pelindung beton & $\mathrm{mm}$ & 40 \\
Rujukan grade bahan & - & API 5L Grade X60 MO PSL2 CS \\
Panjang sambungan pipa & $\mathrm{m}$ & 12.2 \\
Tebal lapisan korosi & $\mathrm{mm}$ & 50 \\
Field joint coating & $\mathrm{mm}$ & 220 \\
\hline
\end{tabular}

Tabel 2. Data Operasional Pipa

\begin{tabular}{lll}
\hline Parameter & Unit & Nilai \\
\hline Pemasangan Pipa & - & Exposed (tidak terkubur) \\
Umur Desain & tahun & 45 \\
Temperature lokasi pemasangan pipa & ${ }^{\circ} \mathrm{C}$ & 25 \\
Content temperature & ${ }^{\circ} \mathrm{C}$ & 40 \\
Temperatur permukaan anoda & ${ }^{\circ} \mathrm{C}$ & 30 \\
\hline
\end{tabular}

Tabel 3. Data Anoda yang Digunakan

\begin{tabular}{ll}
\hline Parameter & Nilai \\
\hline Celah gelang anoda $($ gap $)$ & $75 \mathrm{~mm}$ \\
Desain umur anoda & 45 Tahun \\
Jenis Bahan Anoda & Paduan aluminium (AI-Zinc-In) \\
Efisiensi Elektrokimia dalam Air Laut pada Suhu Sekitar $\left(25^{\circ} \mathrm{C}\right)$ & 2000 A-jam $/ \mathrm{kg}$ \\
Ketebalan anoda $\left(\mathrm{t}_{\mathrm{a}}\right)$ & $40 \mathrm{~mm}$ \\
Massa jenis anoda $(\boldsymbol{\rho} \mathrm{a})$ & $2750 \mathrm{~kg} / \mathrm{m}^{3}$ \\
Panjang anoda $\left(\mathrm{L}_{\mathrm{at}}\right)$ & $400 \mathrm{~mm}$ \\
Core thickness $\left(\mathrm{t}_{\text {core }}\right)$ & $6 \mathrm{~mm}$ \\
Inti per anoda $\left(\mathrm{n}_{\text {core }}\right)$ & 2 \\
Ketebalan lapisan internal anoda ( $\left.\mathrm{t}_{\mathrm{ac}}\right)$ & $0.2 \mathrm{~mm}$ \\
Resistivitas Di Air Laut. & $0,21 \mathrm{ohm}-\mathrm{m}$ (typical) \\
Faktor Pemanfaatan Anoda & 0.80 \\
Toleransi diameter luar pipa (ODtol) & $0 \mathrm{~mm}$ \\
Toleransi diameter dalam pipa (IDtol) & $0 \mathrm{~mm}$ \\
Toleransi fabrikasi (Ftol) & $0 \%$ \\
Lebar inti (Wcore) & $50 \mathrm{~mm}$ \\
Maksimum jarak antar anoda (sesuai spesifikasi) $\left(\mathrm{M}_{\mathrm{AS}}\right)$ & $300 \mathrm{~m}$ \\
\hline
\end{tabular}

\subsection{Penentuan Total Anoda yang Dibutuhkan}

Dalam penentuan total anoda yang dibutuhkan untuk memproteksi pipa, terdapat 4 faktor yang memengaruhi, yaitu:

a. Berdasarkan massa anoda [3] 
1) Persamaan yang digunakan untuk menentukan total anoda berdasarkan massa anoda:

$$
N_{m c d}=\frac{M_{t o t}}{M_{a d}}
$$

2) Persamaan yang digunakan untuk menentukan jarak antar anoda berdasarkan massa anoda:

$$
S P_{m}=\frac{\frac{\left(L_{\text {end }}-L_{\text {start }}\right)}{L_{j}}}{N_{m c d}}
$$

Berdasarkan persamaan (1), $\mathrm{N}_{\text {mcd }}$ adalah jumlah anoda yang di butuhkan (buah), Mtot adalah Total massa anoda yang dibutuhkan $(\mathrm{kg})$ dan Mad adalah Massa per Anoda (kg).

Berdasarkan persamaan (2), $\mathrm{SP}_{\mathrm{m}}$ adalah Rata-rata persyaratan jarak antar anoda (m), Lend adalah Panjang akhir pipa (m), Lstart adalah panjang awal pipa (m), dan Lj adalah Panjang sambungan pipa (m).

b. Berdasarkan Kepadatan Arus

1) Persamaan yang digunakan untuk menentukan total anoda berdasarkan kepadatan arus:

$$
N_{f c d}=\frac{I_{c f}}{I_{a f}}
$$

2) Persamaan yang digunakan untuk menentukan jarak antar anoda berdasarkan kepadatan arus:

$$
S P_{f}=\frac{\frac{\left(L_{\text {end }}-L_{\text {start }}\right)}{L_{j}}}{N_{f c d}}
$$

Berdasarkan persamaan (3), $\mathrm{N}_{\text {fcd }}$ adalah jumlah anoda yang di butuhkan (buah), $\mathrm{I}_{\mathrm{cf}}$ adalah kepadatan arus ratarata (A) dan $\mathrm{I}_{\mathrm{af}}$ adalah Output arus akhir anoda (A).

Berdasarkan persamaan (4), $\mathrm{SP}_{\mathrm{f}}$ adalah Rata-rata persyaratan jarak antar anoda (m), Lend adalah Panjang akhir pipa (m), $\mathrm{L}_{\text {start }}$ adalah panjang awal pipa (m), dan Lj adalah Panjang sambungan pipa (m).

c. Berdasarkan faktor pelemahan anoda

1) Persamaan yang digunakan untuk menentukan total anoda berdasarkan faktor pelemahan anoda:

$$
N_{m}=\frac{L_{\text {end }}-L_{\text {start }}}{\text { jarak antara } 2 \text { sambungan }}
$$

2) Persamaan yang digunakan untuk menentukan jarak antar anoda berdasarkan faktor pelemahan anoda:

$$
S P_{m}=\frac{\frac{\left(L_{e n d}-L_{\text {start }}\right)}{L_{j}}}{N_{\operatorname{mar}}}
$$

Berdasarkan persamaan (5), $\mathrm{N}_{\mathrm{m}}$ adalah jumlah anoda yang di butuhkan (buah).

Berdasarkan persamaan (6), $\mathrm{SP}_{\mathrm{m}}$ adalah Rata-rata persyaratan jarak antar anoda (m), $\mathrm{L}_{\text {end }}$ adalah Panjang akhir pipa (m), $\mathrm{L}_{\text {start }}$ adalah panjang awal pipa (m), dan $\mathrm{Lj}$ adalah Panjang sambungan pipa (m).

d. Berdasarkan jarak maksimal antar anoda [2]

1) Persamaan yang digunakan untuk menentukan total anoda berdasarkan jarak maksimal antar anoda:

$$
N_{\text {mar }}=\frac{L_{\text {end }}-L_{\text {start }}}{M_{A S}}
$$


2) Persamaan yang digunakan untuk menentukan jarak antar anoda berdasarkan jarak maksimal antar anoda:

$$
S P_{\text {mas }}=\frac{\frac{\left(L_{\text {end }}-L_{\text {start }}\right)}{L_{j}}}{N_{\text {mar }}}
$$

Berdasarkan persamaan (5), $\mathrm{N}_{\text {mar }}$ adalah jumlah anoda yang di butuhkan (buah).

Berdasarkan persamaan (6), $\mathrm{SP}_{\text {mas }}$ adalah Rata-rata persyaratan jarak antar anoda (m), Lend adalah Panjang akhir pipa (m), $\mathrm{L}_{\text {start }}$ adalah panjang awal pipa $(\mathrm{m})$, dan $\mathrm{Lj}$ adalah Panjang sambungan pipa (m).

Berdasarkan faktor diatas, di ketahui bahwa faktor yang digunakan dalam menentukan jumlah dan jarak pemasangan antar anoda adalah faktor jarak maksimal antar anoda (biasanya digunakan pada rangkaian pipa panjang). Untuk megetahui apakah perhitungan yang dihasilkan sesuai dengan yang dibutuhkan dilapangan, maka perlu digunakan persamaan rasio kecenderungan retak, yaitu:

$$
C P R=\frac{\pi \times L_{a t} \times I D_{a}}{5 \times t_{a}^{\wedge} 3}
$$

Dimana:

CPR adalah Rasio kecenderungan retak, nilaitr: 3.14159265358979323846, nilai IDa adalah diameter dalam anoda $(\mathrm{mm})$, nilai ta adalah ketebalan anoda $(\mathrm{mm})$. Dalam penentuan rasio keretakan ini, nilai CPR harus kurang dari $5 \mathrm{~mm}^{-1}$.

\subsection{Rekapitulasi Hasil Penelitian}

Berdasarkan persamaan yang digunakan, didapatkan hasil sebagai berikut:

Tabel 4. Rekapitulasi Hasil Penelitian

\begin{tabular}{lll}
\hline Deskripsi & Unit & Nilai \\
\hline Diameter luar pipa & $\mathrm{mm}$ & 406.4 \\
Panjang sambungan pipa & $\mathrm{m}$ & 12.2 \\
Panjang pipa & $\mathrm{m}$ & 135000 \\
Luas permukaan pipa & $\mathrm{m}^{2}$ & 172360 \\
Umur desain & Tahun & 45 \\
Tebal anoda & $\mathrm{mm}$ & 40 \\
Massa jenis anoda & $\mathrm{Kg} / \mathrm{m}^{3}$ & 2750 \\
Panjang anoda & $\mathrm{mm}$ & 400 \\
Jarak antar anoda & $\mathrm{m}$ & 300 \\
Total anoda yang dibutuhkan & buah & 450 \\
\hline
\end{tabular}

\subsection{Jarak Antar Anoda}

Penempatan/pemasangan anoda korban dideskripsikan pada Gambar 4. Rancangan dipasang dengan cara di las termit untuk menghubungkan antara anoda korban dengan pipa baja.

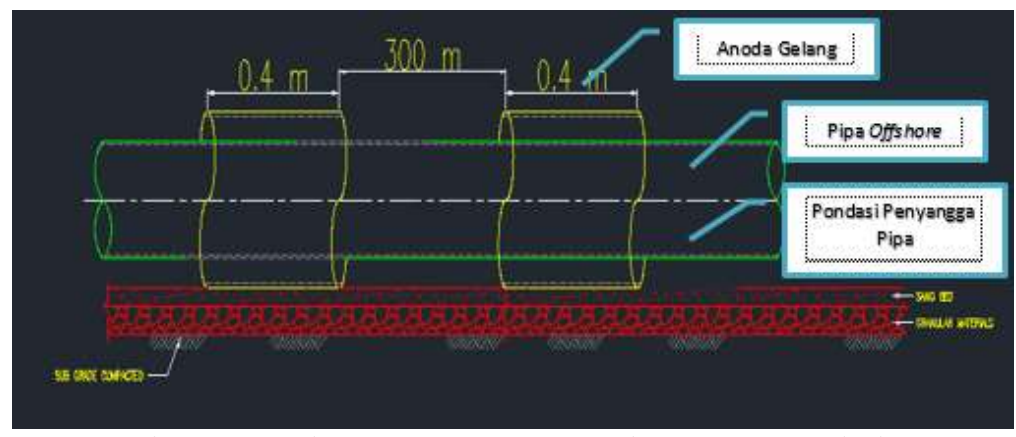

Gambar 4. Usulan pemasangan anoda (tanpa penskalaan) 


\subsection{Rancangan Biaya yang Dibutuhkan}

Rancangan biaya yang akan diperlukan dalam pengadaan per anoda gelang diketahui melalui situs penjualan material internasional [10]. Dengan menggunakan harga maksimal, diketahui analisis biayanya adalah:

Tabel 5. Analisa ekonomis proteksi katodik anoda tumbal

\begin{tabular}{|c|c|c|c|c|c|}
\hline No & $\begin{array}{l}\text { Jenis } \\
\text { Anoda }\end{array}$ & $\begin{array}{l}\text { Total Unit } \\
\text { (Buah) }\end{array}$ & $\begin{array}{l}\text { Biaya Material } \\
\text { Satuan (Rp) }\end{array}$ & Total (Rp) & Keterangan \\
\hline 1 & Gelang & 450 & 731.034 & $328,965,300$ & $\begin{array}{l}\text { Packaged Al-Alloy Half } \\
\text { Bracelet Squared Ends }\end{array}$ \\
\hline \multicolumn{2}{|c|}{ Jumlah } & & & $\operatorname{Rp} 328.965 .300$ & \\
\hline
\end{tabular}

\section{KESIMPULAN}

Setelah melakukan pengolahan data mengenai analisis kebutuhan sistem proteksi katoda metode anoda korban dengan menggunakan anoda berupa anoda gelang, berikut merupakan kesimpulan yang didapatkan.

Total anoda yang dibutuhkan untuk pipa sepanjang $13,5 \mathrm{~km}$ dan umur desain selama 45 tahun adalah 450 buah dan berat keseluruhan anoda adalah $21671.66 \mathrm{~kg}$. Panjang masing-masing anoda adalah $400 \mathrm{~mm}$, tebal anoda $40 \mathrm{~mm}$, dan luas permukaan per anoda adalah $0.623 \mathrm{~m} 2$. Jarak pemasangan antar anoda yang digunakan adalah 300m. Biaya yang dibutuhkan untuk pembuatan proteksi katodik ini adalah Rp328.965.300 dengan harga per anoda Rp 731.034.

\section{UCAPAN TERIMA KASIH}

Ucapan terima kasih yang pertama ingin saya tujukan kepada Departemen Teknik Kelautan Universitas Hasanuddin yang telah membimbing penulis dalam menyelesaikan segala tugas dan penelitian selama perkuliahan. Kedua, ucapan terima kasih saya sampaikan kepada PT. ZEE Indonesia yang telah membimbing dan mengarahkan penulis selama kerja praktek serta dalam pengambilan data dari proyek perusahaan yang pernah dikerjakan.

\section{DAFTAR PUSTAKA}

[1] Bethune, K. And Hartt, "A Novel Approach To Cathodic Protection Design For Marine Pipelines: Part II Applicability Of The Slope Parameter Method", Presented At Corrosion, Paper No.00674, 2000.

[2] DNV GL-RP F103, Cathodic Protection Of Submarine Pipelines, Det Norke Veritas Industry AS, Hovik, 2016.

[3] ISO 15589-2, "Petroleum, Petrochimical And Natural Gas Industries-Chatodic Protecti0n Of Pipeline Transportation System - Part 2:Offshore Pipelines", International Organization For Standardization, Washington, DC, 2012.

[4] Jones, D.A., Principles And Prevention Of Corrosion, First Edition, Macmillan Inc., New York, Pg. 437-445,1992.

[5] Kurnia, Dadang, Perancangan Sistem Proteksi Katodik (Cp) Anoda Korban Pada Pipa Baja, Universitas Pamulang : Pamulang, 2016.

[6] Mulyono, Pribadi Ridzky.,Perancangan Sistem Proteksi Anoda Tumbal Pada Pipa Baja Api 51 Grade B Dengan Variasi Jumlah Coating Yang Dipasang Dalam Tanah, Institut Teknologi Sepuluh Nopember : Surabaya, 2017.

[7] Peabody,Control Of Pipeline Corrosion 2nd Edition, 2001.

[8] Sunde, E.D., Earth Conduction Effects In Transaction Systems, Dover Publishing Inc., New York, NY, Pg. 70-73, 1968.

[9] Www.Corrosion-Doctors.Org/Lnhibitors/Lessonl 1 .Htm. Diakses Pada 29 April 2020

[10] Www.Bukalapak.Com. Diakses Pada Tanggal 30 Juni 2020 